\title{
Incidence and mortality rates of kidney cancers in Iran compared to its proportion throughout the world
}

\author{
Elham Goodarzi ${ }^{1}$, Seyedeh Leila Dehghani ${ }^{2}$, Zaher Khazaei ${ }^{3 *}$ \\ ${ }^{1}$ Social Determinants of Health Research Center, Lorestan University of Medical Sciences, Khorramabad, Iran \\ ${ }^{2}$ Behbahan Faculty of Medical Sciences, Behbahan, Iran \\ ${ }^{3} \mathrm{MSc}$ in Epidemiology, Student Research Committee, Sabzevar University of Medical Sciences, Sabzevar, Iran
}

\section{A R T I C L E I N F O}

\section{Article Type:}

Original

\section{Article History:}

Received: 10 June 2018

Accepted: 3 July 2018

ePublished: 29 July 2018

\section{Keywords:}

Incidence

Mortality

Kidney cancer

Iran

Renal cell carcinoma

Malignancy

\begin{abstract}
A B S T R A C T
Introduction: Kidney cancer was considered as the ninth common cancer worldwide. Its incidence and mortality has been increasing for decades. However, in recent years in many countries, there is a downward trend.

Objectives: This study sought to evaluate the incidence and mortality rates of renal cancers in Iran compared to its proportion throughout the world.

Materials and Methods: All mortality and incidence rates of all countries were extracted from the Global Cancer Project (GLOBOCAN) (data of 2012). The methods of estimation were quality of the estimation and country-specific that was dependent on the quality and on the amount of the available data of each country.

Results: The rates have been shown in eight categories; world, very high human development, high human development, medium human development, low human development, less developed, more developed regions in addition to Iran. The rates of Iran were close to medium human developed region rates. In Iran, 1641 kidney cancers cases have been registered which 981 men and 660 women were reported with an overall incidence rate of 1.9 per 100000 which is less than world incidence rate for kidney cancers. In Iran, the highest incidence was also among patients with age of 75 years and more. Additionally, the lowest incidence rates were among age groups of less than 15 years and age group of 45 - 49 years.

Conclusion: Considering the lower incidence and mortality rates of kidney cancer in Iran compared to other regions of the world, conducting more studies to find related-risk factors to decline the incidence rates of disease would be necessary.
\end{abstract}

Implication for health policy/practice/research/medical education:

The difference of kidney cancer between Iran and other parts of the world could be due to different effects of risk factors on the Iranian population.

Please cite this paper as: Goodarzi E, Dehghani SL, Khazaei Z. Incidence and mortality rates of kidney cancers in Iran compared to its proportion throughout the world J Nephropharmacol. 2018;7(2):137-144.

\section{Introduction}

Kidney cancer was the 13th most common cancer worldwide in 2008 (1) and ninth in 2012 (2) with renal cell carcinoma (RCC) as $90 \%$ of all renal cancers (3) with no completely defined etiology (4). In fact, kidney cancers could be accounted for about three percent of all cancers worldwide (5). In addition, long-term (from 1975 to 2009) and short-term (from 2000 to 2009) trends were examined for incidence and mortality of kidney cancer rates in the United States using the classification of disease stage. They found a persisting rising trend in the incidence and mortality of localized RCC (6).

The incidence of kidney cancers has been increased in the world from the early 1970s until the mid-1990s but it has been stabilized or declined in various countries (7). However, the mortality rates have increased across Europe from the 1980s to 1990s (8) with increasing kidney cancers incidence rate of $2 \%$ per year in previous decades (9). In the European Union (EU) countries, the estimated age-standardized kidney cancers' incidence rates per 100000 Europeans were 15.8 and 7.1 among men and women, respectively. Furthermore, the highest kidney 
cancers' rates were in the Czech Republic, Estonia m Iceland, Latvia and Lithuania compared to lowest rates in Portugal, Cyprus and Romania (10). In fact, the increasing of kidney cancers' incidence has been observed in many countries in the recent years as well as a substantial reduction in mortality rates in other countries, except for Eastern Europe with increasing mortality rates from kidney cancer. In addition, it has been predicted that, by 2030, Brazil and Ecuador will have the highest incidence in men and women which, requiring urgent necessity for health policy planning using healthcare resources (11). Although the general increasing trend of RCC incidence has shown a peak, however, in some countries there was even a decrease in incidence and mortality of RCC (3), such as Finland, the Netherlands, Poland and Sweden (12).

Despite the lower RCC incidence of Iranian population compared to the Western population, there was a slow rising trend of the RCC incidence from 2003 to 2009 in Iran with higher rates among men than women. This finding may be due to improved national cancer registry or changes in RCC risk factors (5).

\section{Objectives}

This study sought to evaluate the mortality and incidence rates of renal cancers in Iran compared to its proportion throughout the world.

\section{Materials and Methods \\ Study design}

The methods of estimation were country-specific and the quality of the estimation was dependent on the quality and on the quantity of the available data of each country. Theoretically, there are numerous estimation methods. However, due to the variety and the complexity of these methods, establishment of an overall quality score for the simultaneously combination of mortality and incidence rate estimation is nearly impossible. However, there was an alphanumeric scoring system that individually could describe the availability of incidence and mortality data established at the country level. Therefore, the combined score could be suitable for each country with an aim of supporting a broad indication of the estimation robustness.

\section{Sources}

Availability of incidence data can be assigned into seven categories including (5);

A. High quality national data or high quality regional (coverage more than 50\%)

B. High-quality regional (coverage among $10 \%$ to $50 \%$ )

C. High-quality regional (coverage less than 10\%)

D. National data (rates)

E. Regional data (rates)

F. Frequency data

G. No data

National statistics are collated and made available by the WHO for countries with available vital registration.
Availability of mortality information can be assigned into six categories as follows:

1. High quality complete vital registration.

2. Medium quality complete vital registration.

3. Low quality complete vital registration.

4. Incomplete or sample vital registration.

5. Other sources (cancer registries and verbal autopsy surveys).

6. No data

\section{Age-specific incidence rate (ASIR)}

The methods to estimate the gender- and age-specific incidence rates of cancer for a specific country could be one of the following nine broad categories, in priority order (5);

1. Rates projected to 2012 (38 countries).

2. Most recent rates applied to 2012 population (20 countries).

3. Estimated from national mortality by modelling, using incidence mortality ratios derived from recorded data in country-specific cancer registries (13 countries).

4. Estimated from national mortality estimates by modelling, benefitting incidence mortality ratios derived from recorded data in local malignancy registries in neighboring countries (9 European countries).

5. Estimated from national mortality estimates using modelled survival (32 countries).

6. Estimated as the weighted average of the local rates (16 countries).

7. One cancer registry covering part of a country is applicable as representative of the country profile (11 countries).

8. Age/gender-specific rates for "all cancers" were partitioned benefiting data on relative frequency of different cancers (by age and gender) (12 countries).

9. The rates are those of neighboring countries or registries in the same area (33 countries).

Depending upon the degree of detail and accuracy of the national mortality data, six methods could be utilized in the following order of priority;

\section{Age-specific mortality rate (ASMR)}

1. Rates projected to 2012 (69 countries).

2. Most recent rates applied to 2012 population (26 countries).

3. Estimated as the weighted average of regional rates (1 country).

4. Estimated from national incidence estimates by modelling, using country-specific survival (2 countries).

5. Estimated from national incidence estimates using modelled survival (83 countries).

6. The rates are those of neighboring countries or registries in the same area (3 countries). 


\section{Ethical issues}

Data for each country and region are analyzed in general and incidence and mortality indicators are reported in general for each country, and the information used in this paper is derived from information extracted from Global Cancer Project (GLOBOCAN) in 2012 available at http:// globocan.iarc.fr/Default.aspx. We processed these raw data with regard to its reference. The research followed the tenets of the Declaration of Helsinki.

\section{Statistical analysis}

All data were collected and were entered into SPSS (version 20.0, SPSS Inc., Chicago, IL, USA) and evaluated by using $t$ test and Pearson test. All incidence and mortality rates have been standardized based on age. $P<0.05$ was considered as statistically significant.

\section{Results}

Figures 1 and 2 show the distribution of incidence and mortality rates of kidney cancer, respectively. Figures show a huge geographically difference between the rates of various regions.

The incidence and mortality rates of kidney cancer in Iran and other parts of the world in all age groups based on gender have been presented in Table 1. The rates have

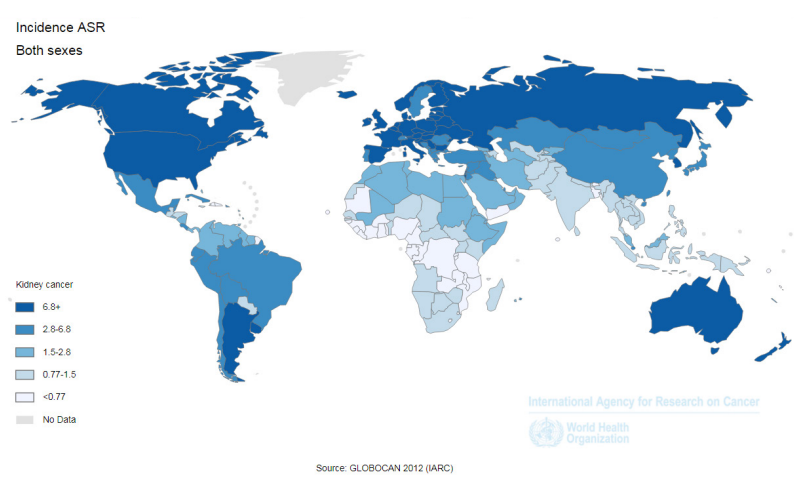

Figure 1. Distribution of the standardized incidence rate of kidney cancer in the world at 2012 [extracted from GLOBOCAN].

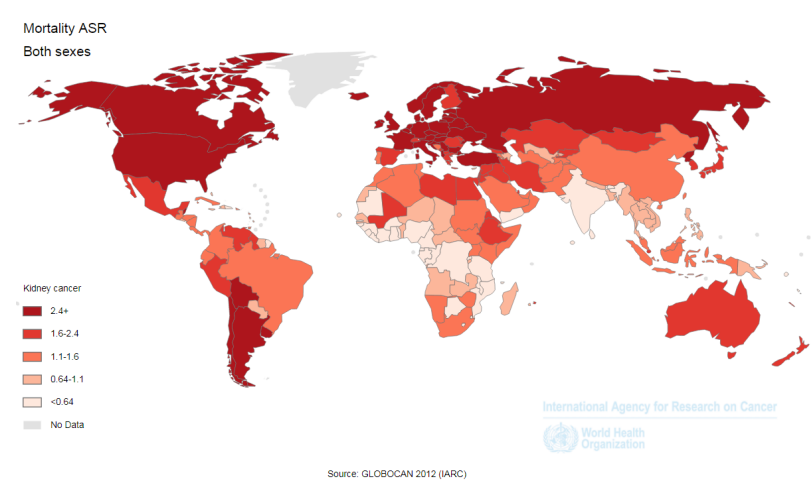

Figure 2. Distribution of the standardized mortality rate of kidney cancer in the world at 2012 [extracted from GLOBOCAN]. been shown in eight categories; world, very high human development, high human development, medium human development, low human development, less developed, more developed regions in addition to Iran. It can be seen that the rates of Iran were close to medium human developed region rates (Table 1 and Figure 3). In 2012, around 6657519 new cancer cases (all cancers) has been registered which 337860 of these cases were kidney cancer (5\%), with 213942 and 123936 cases in men and women, respectively. The overall world incidence of kidney cancer was 2.4 per 100000 from 3.3 to 1 per 100000 as the highest and lowest incidence rates, respectively. In Iran, 1641 kidney cancer cases have been registered of which 981 men and 660 women were reported with an overall incidence rate of 1.9 per 100000 which is less than world incidence rate of kidney cancer (Table 1 and Figure 3 ).

Among 6657519 new world cancer cases (all cancers) in 2012, the age group of 75 years and more were the most common age for cancer incidence with 337860 cases (5\%). The highest and lowest incidence rates of kidney cancers were 35 and 0.5 per 100000 among the age group of 75 years and more and age group of less than 40 years, respectively. In Iran, the highest incidence was also among patients with age of 75 years and more. However, the lowest incidence rates were among age groups of less than 15 years and age group of 45- 49 years (Figure 4).

\section{Discussion}

This study demonstrated that the incidence and mortality rates of Iran were less than overall world rates but close to medium human developed region in 2012. In addition, the percentage of kidney cancer incidence rates from overall world incidence rates have been reported as 5\% in 2012.

As a general fact, incidence rates of RCC are much higher in developed countries, maybe due to more diagnosis in these countries. In addition, declining mortality trends have also been reported in highly developed countries since the 1990s (2), may be due to earlier diagnosis and better treatment. In addition, the kidney cancer incidence rates have been varied geographically (up to 15 times) (2). For example, the highest rates in North America, Australia, and Europe, compared to the lowest rates in Africa, Japan, India and China (9). As a developing country, in Lebanon, kidney cancer is the third most frequent urologic cancer after prostate and bladder cancers (13), with difference in the distribution of histological subtypes of RCC around the world (13).

The observed favorable trend in mortality from kidney cancer as well as its incidence among many European countries might be partly due to the improved diagnosis and treatment methods or maybe the reduced rate of smoking in men (10). Moreover, in spite of increasing the incidence of RCC, it seems that this decline in RCC ageadjusted death rates, might be due to early detection of patients. Furthermore, potential environmental factors 
Amiri et al

Table 1. Incidence and mortality of kidney cancer in Iran and other parts of the world in all group age based on gender

\begin{tabular}{|c|c|c|c|c|c|c|c|}
\hline \multirow{2}{*}{ Population } & \multirow{2}{*}{ Sex } & \multicolumn{3}{|c|}{ Incidence } & \multicolumn{3}{|c|}{ Mortality } \\
\hline & & Number & $\%$ & ASIR & Number & $\%$ & ASMR \\
\hline \multirow{3}{*}{ World } & Both sexes & 337860 & 2.4 & 4.4 & 143406 & 1.7 & 1.8 \\
\hline & Male & 213942 & 2.9 & 6 & 90802 & 2.0 & 2.5 \\
\hline & Female & 123936 & 1.9 & 3 & 52604 & 1.5 & 1.2 \\
\hline \multirow{3}{*}{$\begin{array}{l}\text { Very High human } \\
\text { development }\end{array}$} & Both sexes & 183867 & 3.2 & 9.1 & 65853 & 2.5 & 2.6 \\
\hline & Male & 116890 & 3.8 & 12.5 & 42203 & 2.9 & 3.9 \\
\hline & Female & 66977 & 2.5 & 6.1 & 23650 & 2 & 1.6 \\
\hline \multirow{3}{*}{$\begin{array}{l}\text { High human } \\
\text { development }\end{array}$} & Both sexes & 54493 & 2.6 & 4.7 & 27917 & 2.2 & 2.4 \\
\hline & Male & 32491 & 3.1 & 6.2 & 17461 & 2.6 & 3.4 \\
\hline & Female & 22002 & 2.1 & 3.5 & 10456 & 1.8 & 1.6 \\
\hline \multirow{3}{*}{$\begin{array}{l}\text { Medium human } \\
\text { development }\end{array}$} & Both sexes & 89465 & 1.7 & 2.5 & 41103 & 1.1 & 1.1 \\
\hline & Male & 59205 & 2.1 & 3.4 & 26631 & 1.2 & 1.6 \\
\hline & Female & 30260 & 1.3 & 1.7 & 14472 & 1 & 0.8 \\
\hline \multirow{3}{*}{$\begin{array}{l}\text { Low human } \\
\text { development }\end{array}$} & Both sexes & 9896 & 1 & 1 & 8486 & 1.2 & 0.9 \\
\hline & Male & 5244 & 1.3 & 1.2 & 4472 & 1.4 & 1 \\
\hline & Female & 4652 & 0.9 & 0.9 & 4014 & 1.1 & 0.8 \\
\hline \multirow{3}{*}{ Less developed region } & Both sexes & 137869 & 1.7 & 2.6 & 68458 & 1.3 & 1.3 \\
\hline & Male & 88546 & 2.1 & 3.4 & 42885 & 1.4 & 1.7 \\
\hline & Female & 49323 & 1.3 & 1.8 & 25573 & 1.1 & 0.9 \\
\hline \multirow{3}{*}{ More developed region } & Both sexes & 199991 & 3.3 & 9.2 & 74948 & 2.6 & 2.8 \\
\hline & Male & 125378 & 3.9 & 12.6 & 47917 & 3 & 4.2 \\
\hline & Female & 74613 & 2.6 & 6.2 & 27031 & 2.1 & 1.7 \\
\hline \multirow{3}{*}{ Iran } & Both sexes & 1641 & 1.9 & 2.5 & 1071 & 2 & 1.7 \\
\hline & Male & 981 & 2.2 & 3 & 639 & 2.1 & 2 \\
\hline & Female & 660 & 1.7 & 2.1 & 432 & 1.9 & 1.4 \\
\hline
\end{tabular}

and their possible contribution to the origin of RCC may have improved the diagnosis and treatment of RCC (14). Moreover, the relationship between kidney cancer and human development index (HDI) has been investigated and it was found the higher RCC incidence and mortality rates in developed countries as well as a significant positive correlation between the RCC standardized incidence and mortality rates with HDI and its components (15).

Evidence has shown that RCC incidence rates were much lower among Asians, leading to a higher risk of RCC among whites in comparison with Asians $(1,16)$. African countries have also reported the lowest RCC incidence rates (12). However, the RCC incidence rates were highest among African-Americans people inside the United States (16), which means that race may be accounted for the observed differences in genetic background, access to health care, and lifestyle or environmental risk factors, which it makes impossible to distinguish the effect of these factors (3). Thus, the rising of RCC incidence in specific groups such as African Americans needs special attention. Besides, the role of genetic factors, hypertension, obesity, overweight and cigarette smoking and occupational exposures (asbestos and solvents) and their relation with prognosis and potential mechanisms should also be investigated to find out the potential mechanisms (17).

Regarding the age of patients, RCC is rare among both

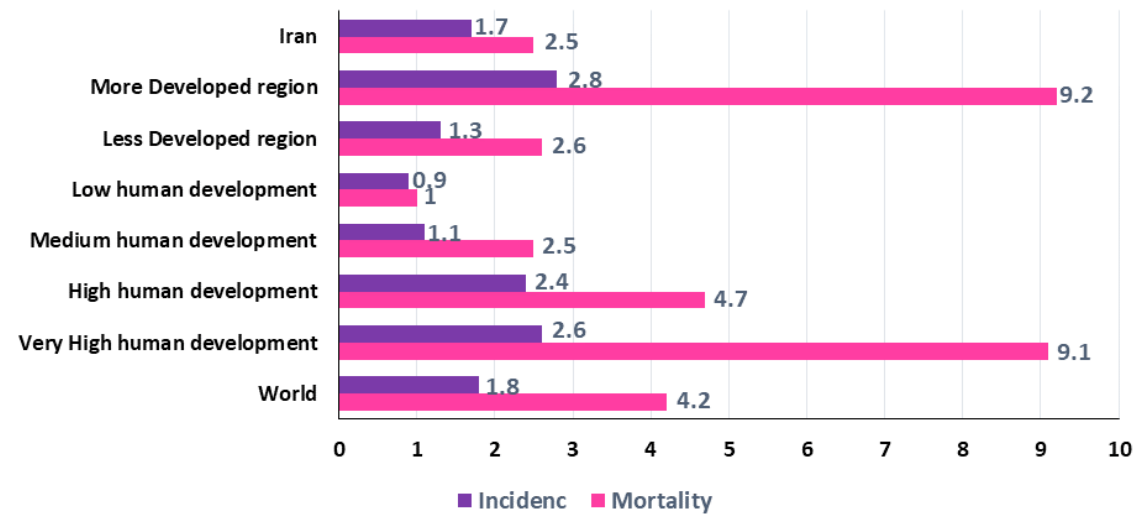

Figure 3. Incidence and mortality of kidney cancer in Iran and other parts of the world. 


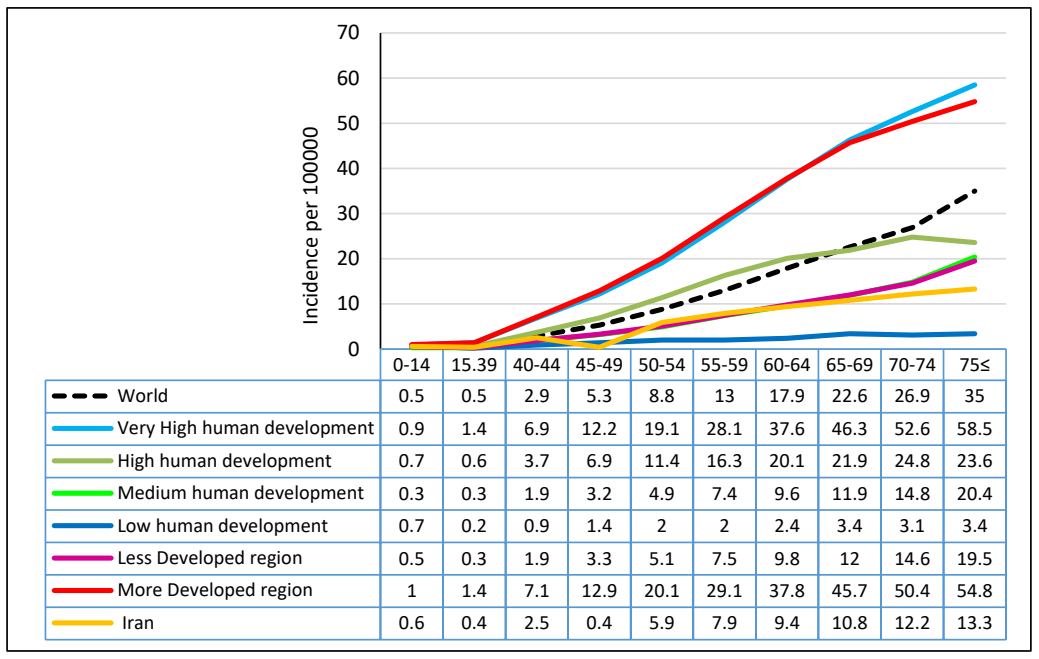

Figure 4. Incidence of kidney cancer in Iran and other parts of the world in both genders based on age.

children (1.9\% to $6 \%$ of childhood cancers) (18) and young adults (less than 40 years old) with $3.5 \%$ to $73 \%$ of all cancers in these age periods (19). In fact, RCC had a better prognosis and survival among younger (less than 40 years old) patients than older (40 years old and more) ones (20). Population growth and aging have resulted to a rapid increase of urological cancer, mainly kidney cancer, despite the reduction in the smoking rate, with the peak age of 50-54 and 65-69 years (21). The highest rates belonged to the age group of 75 years and more, which will be more important in the future due to population ageing.

There are many established risk factors for kidney cancer include demographic risk factors such as race (12), age (16) and gender (1), high proportion of parity in women (7), life style risk factors like cigarette smoking $(22,23)$, physical activity (7) and obesity $(23,24)$, iatrogenic risk factors such as hypertension $(25,26)$ and consumption of antihypertensive medications (26) [although, RCC can also lead to hypertension (27)], acquired renal cystic disease (28), type 2 diabetes (29) and urinary tract infection (30), nutritional and diet factors (mostly protective effect) (31) such as coffee, alcohol and beverage consumption (7, 23,32), high protein consumption (33), occupation [for instance, exposure with trichloroethylene (TCE) and perchloroethylene (PCE) as well as carcinogenic metals (arsenic, cadmium, chromium, lead, and nickel)] (7, 34) and exposure to asbestos (35), polycyclic aromatic hydrocarbons (36), gasoline and other petroleum products (37), genetic factors such as familial and hereditary renal cancer syndromes (38) including von Hippel-Lindau syndrome (VHL) (39), hereditary papillary RCC (38), familial leiomyomatosis RCC (39), Birt-Hogg-Dubé syndrome (BHD) (40) and tuberous sclerosis (25), drugs like analgesics (41), diuretics (42) and estrogens (43).

Environmental exposures are very important for kidney cancer. For example, the observed extra-mortality in women in towns with higher degree of natural radiation in Spain has reflected the potential influence of exposures deriving from the geologic composition of the terrain and its effect on the drinking water (8). In addition, in a study on the effects of arsenic on people over 50 years, a latency pattern of rising mortality from kidney cancer was observed, which can be continued for at least 25 years after the declining of high arsenic exposures (44). In fact, exposure to arsenic through drinking water may be involved with one of the longest cancer latencies of human carcinogens, even about 40 years (45). It means that even after arsenic reduction, the potential incidence of arsenicrelated diseases will remain high for many years after stopping arsenic exposure, Therefore, stopping exposures should be conducted as soon as possible and public health efforts have to continue to reduce mortality and morbidity long after stopping exposures. Long-term interventions may reduce important co-exposures, disease screening, treatment and health services resource planning as well as increasing public awareness of arsenic health effects (45). There is evidence that kidney cancer mortality rates have declined gradually. Additionally, the relationship between arsenic exposure with mortality of kidney cancer has been reported (46).

The main treatment of localized kidney cancer would be the radical nephrectomy. In addition, interleukin and Interferons were the only known effective treatments for metastatic disease. However, nowadays there are new and more efficient treatments (47). Moreover, stage of disease at the initiation of treatment is the most important prognostic factor for RCC survival. The 5-year survival rates are 95\%, $88 \%, 59 \%$ and $20 \%$ for patients with stages of I, II, III and IV, respectively (47). The follow-up schedule of localized RCC after surgery depends on the treatment possibilities based on recurrence. Additionally, CT scans of thorax and abdomen are routinely recommended, with time intervals 
depending on risk factors (48). Moreover, the survival of kidney cancer patients can be influenced by various factors including patient-related prognostic factors (such as socioeconomic background, comorbidities, health care accessibility and performance status), tumor-related prognostic factors (such as morphological features, TNM stage, genetic/molecular markers), and treatment-related prognostic factors (such as immunotherapy, targeted medicine and surgery) (49).

In spite of substantial advances in the diagnosis of RCC, especially imaging techniques for unrelated complaints, approximately $20 \%-30 \%$ of all RCC patients are still diagnosed with metastatic RCC (mRCC) (50). Accordingly, there are many biomarker candidates for prediction of metastatic RCC from plasma, tumor, and host tissues in patients receiving various systemic therapies, but none of them have been validated for clinical use (51). Thus, new treatments with new mechanisms of action relevant to RCC are needed (52). It should be noted that still many patients still die of metastatic RCC. In fact, treatment should be individualized based on own patient risk and to obtain maximal benefit. Every selected drug has to be optimized in terms of its dose and schedule (53). It should be mentioned that for nephrectomy candidates with non-metastatic RCC, pathological stage and lymph node involvement could be very important prognostic factors (54). Moreover, RCC may have an unpredictable time course, with recurrence intervals of even up to 30 years, Therefore, prolonged periods of follow-up may be necessary for these patients (55).

Regular consumption of fruits and vegetables (particularly cruciferous vegetables) can decline the rates of RCC (56). Thus, interventions for decreasing the prevalence of smoking, obesity and hypertension as well as increasing intake of fruits and vegetables might result in the stabilization or reduction of incidence and mortality from kidney cancer. However, some evidence demonstrated that higher body mass index (BMI) before renal surgery may be associated with improved RCC survival (57).

\section{Conclusion}

The difference of kidney cancer between Iran and other parts of the world could be due to different effects of risk factors on the Iranian population. The lower incidence and mortality rates of kidney cancer in Iran compared to other regions of the world, suggesting the conduction of more studies to evaluate the related-risk factors in order to decline the incidence and mortality rates of the disease. The prophylactic actions to prevent the kidney cancer may include keeping the healthy body weight, discontinuing of cigarette smoking, low consumption of alcohol, and increasing the physical activity. In addition, a healthy regimen full of fresh fruits and vegetables might decrease the personal risk. The diagnosis of the primary prophylactic actions in high-risk regions is also necessary to be done.

The main avoidable risk factors of kidney cancer could be cigarette smoking as well as excess body weight and obesity. Thus, primary prevention will be cessation of cigarette smoking with reducing obesity as the most obvious strategies for declining the incidence and mortality from kidney cancer. In addition, according to the important role of hypertension in kidney cancer, early finding of hypertensive patients and their treatment is also required for prevention of disease.

\section{Limitations of the study}

Because quality of cancer registry is different among various countries; therefore, it might affect on the observed cancer incidence and mortality rates and this difference would really be due to difference in the registration of cancer patients. Thus, with improvement of registration process and increasing decision during registering, the difference among countries will indeed be declined.

\section{Acknowledgments}

The authors gratefully acknowledge the many cancer registries worldwide and their staff for their willingness to contribute their data to this exercise.

\section{Authors' contribution}

All authors contributed to the design of the research. EG and $\mathrm{ZKH}$ collected the data. ZKH and EG conducted analysis and interpretation of data. All authors drafted the first version. ZKH, EG and SLD edited the first draft. All authors reviewed, commented and approved the final draft.

\section{Conflicts of interest}

The authors declare no conflict of interest.

\section{Ethical considerations}

Ethical issues (including plagiarism, data fabrication, double publication) have been completely observed by the authors.

\section{Funding/Support}

None.

\section{References}

1. Ferlay J, Shin HR, Bray F, Forman D, Mathers C, Parkin DM. Estimates of worldwide burden of cancer in 2008: GLOBOCAN 2008. Int J Cancer. 2010;127:2893-917. doi: 10.1002/ijc.25516.

2. Znaor A, Lortet-Tieulent J, Laversanne M, Jemal A, Bray F. International variations and trends in renal cell carcinoma incidence and mortality. Eur Urol. 2015;67:519-30. doi: 10.1016/j.eururo.2014.10.002.

3. Ljungberg B, Campbell SC, Choi HY, Jacqmin D, Lee JE, Weikert S, et al. The epidemiology of renal cell carcinoma. Eur Urol. 2011;60:615-21. doi: 10.1016/j. eururo.2011.09.001. 
4. Pascual D, Borque A. Epidemiology of kidney cancer. Adv Urol. 2008:782381. doi: 10.1155/2008/782381.

5. Ferlay J, Soerjomataram I, Dikshit R, Eser S, Mathers $\mathrm{C}$, Rebelo $\mathrm{M}$, et al. Cancer incidence and mortality worldwide: sources, methods and major patterns in GLOBOCAN 2012. Int J Cancer. 2015;136:E359-86. doi: 10.1002/ijc.29210.

6. Gandaglia G, Ravi P, Abdollah F, Abd-El-Barr AE, Becker A, Popa I, et al. Contemporary incidence and mortality rates of kidney cancer in the United States. Can Urol Assoc J. 2014;8:247-52. doi: 10.5489/cuaj.1760.

7. Chow WH, Dong LM, Devesa SS. Epidemiology and risk factors for kidney cancer. Nat Rev Urol. 2010;7:245-57. doi: 10.1038/nrurol.2010.46

8. Lopez-Abente G, Aragones N, Perez-Gomez B, Ramis R, Vidal E, Garcia-Perez J, et al. Kidney cancer mortality in Spain: geographic patterns and possible hypotheses. BMC Cancer. 2008;8:293. doi: 10.1186/1471-2407-8-293.

9. Ferlay J, Parkin DM, Steliarova-Foucher E. Estimates of cancer incidence and mortality in Europe in 2008. Eur J Cancer. 2010;46:765-81. doi: 10.1016/j.ejca.2009.12.014.

10. Levi F, Ferlay J, Galeone C, Lucchini F, Negri E, Boyle P, et al. The changing pattern of kidney cancer incidence and mortality in Europe. BJU Int. 2008;101:949-58. doi: 10.1111/j.1464-410X.2008.07451.x.

11. Wong MCS, Goggins WB, Yip BHK, Fung FDH, Leung $\mathrm{C}$, Fang $\mathrm{Y}$, et al. Incidence and mortality of kidney cancer: temporal patterns and global trends in 39 countries. Sci Rep. 2017;7:15698. doi: 10.1038/s41598-017-15922-4.

12. Karim-Kos HE, de Vries E, Soerjomataram I, Lemmens V, Siesling S, Coebergh JW. Recent trends of cancer in Europe: a combined approach of incidence, survival and mortality for 17 cancer sites since the 1990s. Eur J Cancer. 2008;44:1345-89. doi: 10.1016/j.ejca.2007.12.015.

13. Khafaja S, Kourie HR, Matar D, Sader-Ghorra C, Kattan J. Kidney cancer in Lebanon: a specific histological distribution? Asian Pac J Cancer Prev. 2015;16:363-5.

14. Marumo K, Kanayama H, Miyao N, Nakazawa H, Ozono S, Horie S, et al. Prevalence of renal cell carcinoma: a nationwide survey in Japan, 2002. Int J Urol. 2007;14:479-82.

15. Mohammadian M, Pakzad R, Towhidi F, Makhsosi BR, Ahmadi A, Salehiniya $\mathrm{H}$. Incidence and mortality of kidney cancer and its relationship with HDI (Human Development Index) in the world in 2012. Clujul Med. 2017;90:286-293. doi: 10.15386/cjmed-691.

16. Chow WH, Devesa SS. Contemporary epidemiology of renal cell cancer. Cancer J. 2008;14:288-301. doi: 10.1097/ PPO.0b013e3181867628.

17. Rubagotti A, Martorana G, Boccardo FM. Epidemiology of Kidney Cancer. Eur Urol Suppl. 2006;5:558-565.

18. Indolfi P, Spreafico F, Collini P, Cecchetto G, Casale F, Terenziani $\mathrm{M}$, et al. Metastatic renal cell carcinoma in children and adolescents: a 30-year unsuccessful story. J Pediatr Hematol Oncol. 2012;34:e277-81.

19. Gillett MD, Cheville JC, Karnes RJ, Lohse CM, Kwon $\mathrm{ED}$, Leibovich $\mathrm{BC}$, et al. Comparison of presentation and outcome for patients 18 to 40 and 60 to 70 years old with solid renal masses. J Urol. 2005;173:1893-6. doi: 10.1097/01.ju.0000158157.57981.80.

20. Taccoen X, Valeri A, Descotes JL, Morin V, Stindel E, Doucet L, et al. Renal cell carcinoma in adults 40 years old or less: young age is an independent prognostic factor for cancer-specific survival. Eur Urol. 2007;51:980-7. doi: 10.1016/j.eururo.2006.10.025

21. Song W, Jeon HG. Incidence of kidney, bladder, and prostate cancers in Korea: An update. Korean J Urol. 2015;56:422-8. doi: 10.4111/kju.2015.56.6.422.

22. Hunt JD, van der Hel OL, McMillan GP, Boffetta P, Brennan P. Renal cell carcinoma in relation to cigarette smoking: meta-analysis of 24 studies. Int J Cancer. 2005;114:101-8.

23. Asal NR, Risser DR, Kadamani S, Geyer JR, Lee ET, Cherng N. Risk factors in renal cell carcinoma: I. Methodology, demographics, tobacco, beverage use, and obesity. Cancer Detect Prev. 1988;11:359-77.

24. Pischon $\mathrm{T}$, Lahmann $\mathrm{PH}$, Boeing $\mathrm{H}$, Tjonneland $\mathrm{A}$, Halkjaer J, Overvad K, et al. Body size and risk of renal cell carcinoma in the European Prospective Investigation into Cancer and Nutrition (EPIC). Int J Cancer. 2006;118:72838. doi: 10.1002/ijc.21398.

25. Janout V, Janoutova G. Epidemiology and risk factors of kidney cancer. Biomed Pap Med Fac Univ Palacky Olomouc Czech Repub. 2004;148:95-101.

26. Weikert S, Boeing H, Pischon T, Weikert C, Olsen A, Tjonneland $\mathrm{A}$, et al. Blood pressure and risk of renal cell carcinoma in the European prospective investigation into cancer and nutrition. Am J Epidemiol. 2008;167:438-46. doi: $10.1093 /$ aje/kwm321.

27. Lindblad P. Epidemiology of renal cell carcinoma. Scand J Surg. 2004;93:88-96

28. Miller LR, Soffer O, Nassar VH, Kutner MH. Acquired renal cystic disease in end-stage renal disease: an autopsy study of 155 cases. Am J Nephrol. 1989;9:322-8. doi: 10.1159/000167988.

29. Zucchetto A, Dal Maso L, Tavani A, Montella M, Ramazzotti $\mathrm{V}$, Talamini R, et al. History of treated hypertension and diabetes mellitus and risk of renal cell cancer. Ann Oncol. 2007;18:596-600.

30. Parker AS, Cerhan JR, Lynch CF, Leibovich BC, Cantor KP. History of urinary tract infection and risk of renal cell carcinoma. Am J Epidemiol. 2004;159:42-8.

31. Allen NE, Roddam AW, Sieri S, Boeing H, Jakobsen MU, Overvad $\mathrm{K}$, et al. A prospective analysis of the association between macronutrient intake and renal cell carcinoma in the European Prospective Investigation into Cancer and Nutrition. Int J Cancer. 2009;125:982-7. doi: 10.1002/ ijc.24447.

32. Brownson RC. A case-control study of renal cell carcinoma in relation to occupation, smoking, and alcohol consumption. Arch Environ Health. 1988;43:238-41. doi: 10.1080/00039896.1988.9934940.

33. Chow WH, Gridley G, McLaughlin JK, Mandel JS, Wacholder S, Blot WJ, et al. Protein intake and risk of renal cell cancer. J Natl Cancer Inst. 1994;86:1131-9.

34. Moore LE, Boffetta P, Karami S, Brennan P, Stewart PS, Hung $\mathrm{R}$, et al. Occupational trichloroethylene exposure and renal carcinoma risk: evidence of genetic susceptibility by reductive metabolism gene variants. Cancer Res. 2010;70:6527-36. doi: 10.1158/0008-5472.CAN-09-4167.

35. Smith AH, Shearn VI, Wood R. Asbestos and kidney cancer: the evidence supports a causal association. Am J Ind Med. 1989;16:159-66.

36. Mellemgaard A, Engholm G, McLaughlin JK, Olsen JH. Occupational risk factors for renal-cell carcinoma in Denmark. Scand J Work Environ Health. 1994;20:160-5.

37. Wong O, Raabe GK. Critical review of cancer epidemiology in petroleum industry employees, with a quantitative meta- 
analysis by cancer site. Am J Ind Med. 1989;15:283-310.

38. Coleman JA. Familial and hereditary renal cancer syndromes. Urol Clin North Am. 2008;35:563-72; v. doi: 10.1016/j.ucl.2008.07.014.

39. Pfaffenroth EC, Linehan WM. Genetic basis for kidney cancer: opportunity for disease-specific approaches to therapy. Expert Opin Biol Ther. 2008;8:779-90. doi: 10.1517/14712598.8.6.779

40. Hansel DE, Rini BI. Molecular genetics of hereditary renal cancer: new genes and diagnostic and therapeutic opportunities. Expert Rev Anticancer Ther. 2008;8:895905. doi: 10.1586/14737140.8.6.895.

41. Chow WH, McLaughlin JK, Linet MS, Niwa S, Mandel JS. Use of analgesics and risk of renal cell cancer. Int J Cancer. 1994;59:467-70.

42. Hiatt RA, Tolan K, Quesenberry CP, Jr. Renal cell carcinoma and thiazide use: a historical, case-control study (California, USA). Cancer Causes Control. 1994;5:319-25.

43. Asal NR, Geyer JR, Risser DR, Lee ET, Kadamani S, Cherng N. Risk factors in renal cell carcinoma. II. Medical history, occupation, multivariate analysis, and conclusions. Cancer Detect Prev. 1988;13:263-79.

44. Yuan Y, Marshall G, Ferreccio C, Steinmaus C, Liaw J, Bates $\mathrm{M}$, et al. Kidney cancer mortality: fifty-year latency patterns related to arsenic exposure. Epidemiology. 2010;21:103-8. doi: 10.1097/EDE.0b013e3181c21e46.

45. Smith AH, Marshall G, Roh T, Ferreccio C, Liaw J, Steinmaus C. Lung, Bladder, and Kidney Cancer Mortality 40 Years After Arsenic Exposure Reduction. J Natl Cancer Inst. 2018;110:241-249. doi: 10.1093/jnci/djx201.

46. Yang CY, Chiu HF, Wu TN, Chuang HY, Ho SC. Reduction in kidney cancer mortality following installation of a tap water supply system in an arsenic-endemic area of Taiwan. Arch Environ Health. 2004;59:484-8.

47. Rajer M. Kidney cancer. Radiol Oncol. 2007;41:64-71.

48. Escudier B, Eisen T, Porta C, Patard JJ, Khoo V, Algaba F, et al. Renal cell carcinoma: ESMO Clinical Practice Guidelines for diagnosis, treatment and follow-up. Ann
Oncol. 2012;23:vii65-71. doi: 10.1093/annonc/mds227.

49. Schmidt A, Arndt V, Taverna C, Lorez M, the NICER Working Group. Survival Trends for Kidney Cancer Patients in Switzerland. Schweizer Krebsbulletin. 2017;1:78-83.

50. Gupta K, Miller JD, Li JZ, Russell MW, Charbonneau C. Epidemiologic and socioeconomic burden of metastatic renal cell carcinoma (mRCC): a literature review. Cancer Treat Rev. 2008;34:193-205. doi: 10.1016/j.ctrv.2007.12.001.

51. Sonpavde G, Choueiri TK. Biomarkers: the next therapeutic hurdle in metastatic renal cell carcinoma. $\mathrm{Br} \mathrm{J}$ Cancer. 2012;107:1009-16. doi: 10.1038/bjc.2012.399.

52. Choueiri TK, Motzer RJ. Systemic Therapy for Metastatic Renal-Cell Carcinoma. N Engl J Med. 2017;376:354-366. doi: 10.1056/NEJMra1601333.

53. North S, Basappa N, Bjarnason G, Blais N, Canil C, Heng $\mathrm{D}$, et al. Management of advanced kidney cancer: Canadian Kidney Cancer Forum 2013 Consensus Update: Canadian Kidney Cancer Forum 2013. Can Urol Assoc J. 2013;7:23843. doi: 10.5489/cuaj.536.

54. Gurgel MVSA, Alves J Júnior, Vieira GBF, Sales FCD, Lima MVA. Predictors of mortality in patients submitted to nephrectomy for non-metastatic renal cell carcinoma at a referral center in Northeastern Brazil. Rev Col Bras Cir. 2017;44:257-262. doi: 10.1590/0100-69912017003006.

55. Ng CS, Wood CG, Silverman PM, Tannir NM, Tamboli P, Sandler CM. Renal cell carcinoma: diagnosis, staging, and surveillance. AJR Am J Roentgenol. 2008;191:1220-32. doi: 10.2214/AJR.07.3568.

56. Lee JE, Mannisto S, Spiegelman D, Hunter DJ, Bernstein L, van den Brandt PA, et al. Intakes of fruit, vegetables, and carotenoids and renal cell cancer risk: a pooled analysis of 13 prospective studies. Cancer Epidemiol Biomarkers Prev. 2009;18:1730-9. doi: 10.1158/1055-9965.EPI-09-0045.

57. Choi Y, Park B, Jeong BC, Seo SI, Jeon SS, Choi HY, et al. Body mass index and survival in patients with renal cell carcinoma: a clinical-based cohort and meta-analysis. Int J Cancer. 2013;132:625-34. doi: 10.1002/ijc.27639.

Copyright $\odot 2018$ The Author(s); Published by Society of Diabetic Nephropathy Prevention. This is an open-access article distributed under the terms of the Creative Commons Attribution License (http://creativecommons.org/licenses/by/4.0), which permits unrestricted use, distribution, and reproduction in any medium, provided the original work is properly cited. 